\title{
Acute vertebral collapse and cauda equina compression in tertiary syphilis
}

\author{
R. W. GRIFFITHS AND M. J. ROSE
}

From the Regional Neurosurgical Centre, Walton Hospital, Liverpool

SYNOPSIS A patient with observed acute collapse of a lumbar vertebral body developed cauda equina compression. He was known to have contracted syphilis some 20 years before and, while he may well have suffered from tabetic spinal neuroarthropathy, histology of the collapsed vertebra showed features which indicate that an intra-osseous gumma could also have been responsible for his vertebral collapse and subsequent neurological deficit.

A male patient aged 62 years was admitted to another hospital in April 1974 with the history that he had suffered from shooting pains passing into both legs for 10 years. About 20 years previously he had been diagnosed as having primary syphilis, but details of any treatment received were not available. The recent admission was for a worsening of his lower limb pain which was now more constant and associated with bilateral leg weakness which had developed over the course of several weeks.

Lumbar spine radiographs on admission revealed minimal sclerotic changes in the body of L5 vertebra only, but 25 days later, while under observation, he developed acute retention of urine, which was treated by catheterization. At that time his leg weakness prevented him from walking, and repeat lumbar radiographs now revealed marked collapse of the body of L5 vertebra (Figs 1 and 2) so he was transferred to the Neurosurgical Centre.

On admission to Walton Hospital he was noted to have Argyll-Robertson pupils and his lower limbs showed grossly diminished power affecting all muscle groups, absent knee and ankle jerks, flexor plantar responses, and impaired proprioception. There was no loss of sensation in the legs to pinprick and no sensory level was present. No other neurological losses were noted and all lower limb pulses were present and equal. In the abdomen a distended painless bladder was palpable, and rectal examination revealed a moderately enlarged firm prostate.

In view of this picture of acute cauda equina compression, an emergency myelogram was performed. At this same time radiographs of the lumbar spine

(Accepted 22 January 1975.) showed gross destruction of the body of L5 vertebra and some destructive changes in the lower part of the body of L4 vertebra. The radiologist reported that he assumed that this collapse was evidence of $D$ metastatic disease. The myelogram showed an almost complete block to the column of iophendylate at the L3-L4 intervertebral level, and the iophendylate $\mathbb{\Omega}_{\square}$. was displaced backwards at the level of $\mathrm{L} 4$ vertebrao $-\vec{c}$ and indented posteriorly by what appeared to be an $\subseteq$ enlarged and sclerotic lamina. The body of $L 50$ vertebra was noted to be collapsed with preservation $\overrightarrow{\mid} \cdot \overrightarrow{0}$

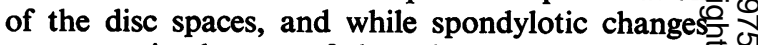
were seen in the rest of the spine no obvious lytic lesions or other areas of vertebral collapse could be found.

Because of the signs and symptoms of cauda equina compression, decompressive lumbar laminectomy was performed.

OPERATION A laminectomy of L4 and L5 vertebrae was performed. No tumour was found in the extradural tissues, but the lamina of L4 vertebra was rather soft. The dura mater appeared to be displaced backwards and exploration anteriorly revealed a cavity in the position of L5 vertebral body. Tissue from the edge of the cavity was sent for histology together with the laminae removed. Good decompression of the cauda equina was obtained.

HISTOLOGY Sections showed chronic granulation tissue, much collagen and fibrocartilage with lymphocytic infiltration in some areas. No tumour was seen. Appearances were regarded as compatible with a chronic inflammatory condition; we suggest that this was a gumma though this is not proven. 


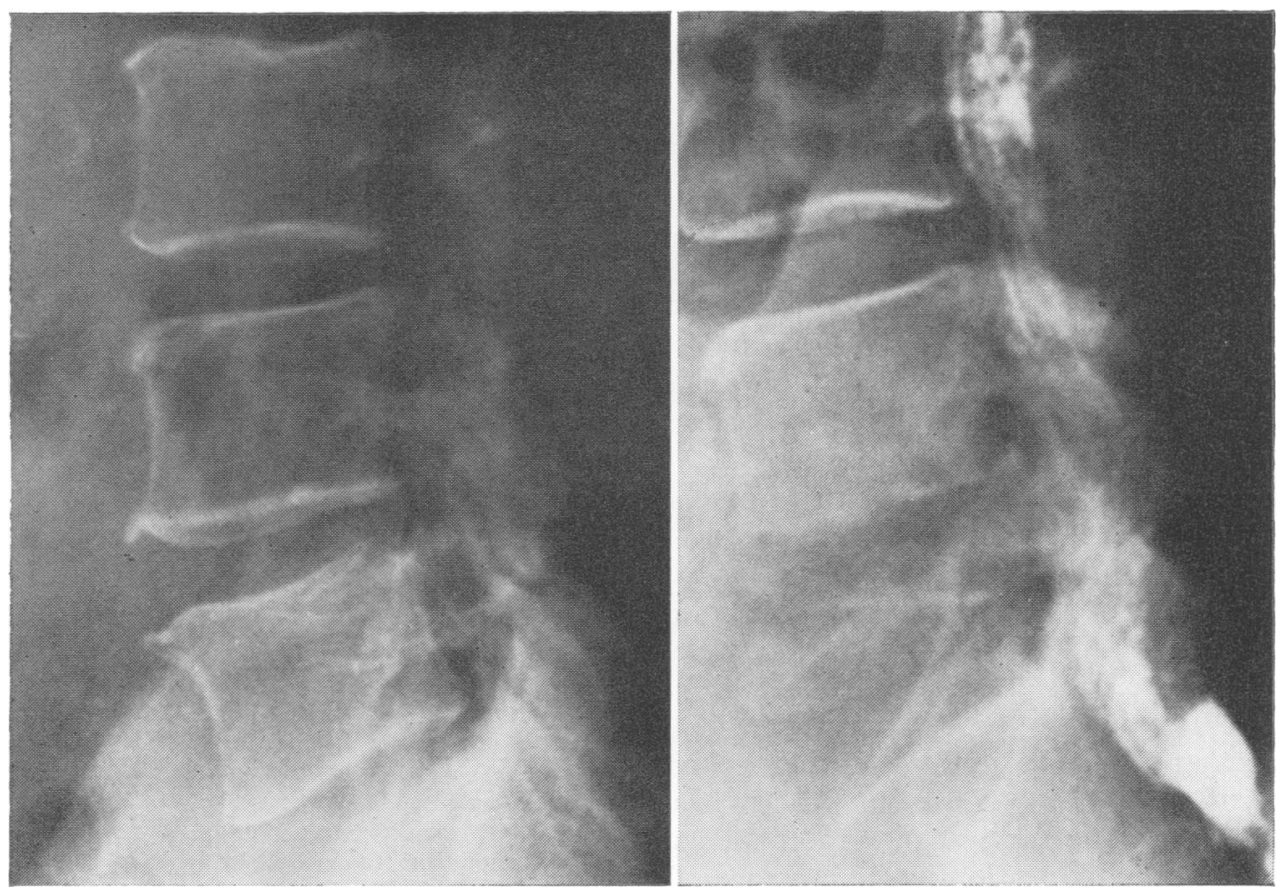

FIG. 1 (left) Initial lumbar radiograph on admission showing minimal sclerotic changes of L5 vertebral body. FIG. 2 (right) Radiograph of lumbar spine at myelography (25 days after Fig. 1) showing marked collapse of L5 vertebral body, and some destruction of the adjacent posterior aspect of L4 vertebral body. The indentation of the iophendylate column at the point of cauda equina compression is also demonstrated.

SEROLOGY In the CSF the Wassermann and PPR tests were negative. Treponemal HA test of blood was positive in a titre of 1 in 16. The cardiolipin WR was weakly reactive. A Reiter protein complement fixation test was weakly reactive, and the FTA absorbed test was positive. These results were considered to be indicative of a treponemal infection so he was treated postoperatively with procaine penicillin 1.2 Mu daily for 20 injections.

Over the course of six weeks postoperatively the power in the patient's legs gradually improved and he regained control of micturition. At the time of writing he was able to walk with the aid of a Zimmer frame and no longer needed a catheter. Examination at this stage revealed normal lower limb reflexes but the proprioceptive loss remained.

\section{DISCUSSION}

Spinal tabetic neuroarthropathy as a cause of spinal cord compression is well documented (McNeel and Ehni, 1969; Ramani and Sengupta,
1973) and Thomas (1952) in an extensive review of the topic stated that syphilitic infection of the lumbar spine was uncommon.

In tabetic spinal neuroarthropathy vertebral body sclerosis and narrowing of the disc space with angulation of the vertebral column are the pathognomonic findings. Compression of the vertebral bodies has been described in this condition, but only in association with disc space disorganization and kyphosis.

Gumma of the vertebrae is not mentioned as a cause of vertebral collapse or spinal cord compression in standard textbooks (Mercer and Duthie, 1964; Turek, 1967; King and Nicol, 1969; Northfield, 1973), nor have we found any reference to it in the recent literature. With the decline in the prevalence of advanced stages of syphilitic infection this case is to be regarded with some interest.

The patient reported here was known to have 
suffered from primary syphilis some 20 years ago and, at that time, as far as can be ascertained, he had received inadequate treatment. He had suffered symptoms of tabes dorsalis for 10 years before his recent admission when he was found to have the stigmata of tertiary syphilis associated with positive serology.

Storey (1964) described a case of vertebral collapse with tabes dorsalis associated with urinary retention, bladder function returning to normal after spinal cord decompression, but unfortunately no further details are given.

The importance of our case lies, not so much in its rarity, but in the fact that the patient presented the all too familiar picture of vertebral collapse and spinal cord compression which so frequently proves to be caused by metastatic malignant disease. However, it would have been sad indeed if malignancy had been assumed in this patient and perhaps nothing further done.

A recent report by Jameson (1974) has described worthwhile survival in some patients with spinal cord compression in the presence of malignant disease, but such as he describes are the exceptions and most cases have a gloomy outlook, so much so that many are not submitted to operation.

While malignancy will all too often be found to be the cause of cord compression in patients with vertebral collapse, the case reported here proves the exception to the rule, and should alert the clinician to any similar case when a history of past syphilis and/or positive serology coexist in a patient with signs of spinal cord or cauda equina compression.

We wish to thank Mr R. H. Hannah, under who's care this patient was admitted, for allowing us to report the details of this case, and Mrs Sellars of the University Department of Radiodiagnosis for the photography of the radiographs.

\section{REFERENCES}

Jameson, R. M. (1974). Prolonged survival in paraplegia due to metastatic spinal tumours. Lancet, 1, 1209-1211.

King, A., and Nicol, C. (1969). Venereal Disease, 2nd edn. Baillière: London.

McNeel, D. P., and Ehni, G. (1969). Charcot joint of the lumbar spine. Journal of Neurosurgery, 30, 55-61.

Mercer, Sir W., and Duthie, R. B. (1964). Orthopaedic Surgery, 6th edn. Arnold: London.

Northfield, D. W. C. (1973). Surgery of the Central Nervous System. Blackwell: Oxford.

Ramani, P. S., and Sengupta, R. P. (1973). Cauda equina $0^{\infty}$ compression due to tabetic arthropathy of the spine. $\bar{O}$ ir Journal of Neurology, Neurosurgery, and Psychiatry, 36, 260-264.

Storey, G. (1964). Charcot's joints. British Journal of Venereal $\stackrel{\mathrm{Q}}{\mathrm{Q}}$ Disease, 40, 109-117.

Thomas, D. F. (1952). Vertebral osteoarthropathy of Charcot's disease of the spine. Review of the literature and a report of two cases. Journal of Bone and Joint Surgery, 34B, 248-255.

Turek, S. L. (1967). Orthopaedics: Principles and Their Application, 2nd edn. Lippincott: Philadelphia. 